\title{
O PAPEL INTERATIVO COMO HÁBITO DE TRABALHO EM GRUPO DO GESTOR ESCOLAR
}

\section{ARTIGO DE REVISÃO}

BARROSO, Marcline da Silva ${ }^{1}$

BARROSO, Marcline da Silva. O papel interativo como hábito de trabalho em grupo do Gestor Escolar. Revista Científica Multidisciplinar Núcleo do Conhecimento. Ano 05, Ed. 09, Vol. 07, pp. 49-59. Setembro de 2020. ISSN: 24480959, Link de acesso: https://www.nucleodoconhecimento.com.br/educacao/gestor$\underline{\text { escolar }}$

\section{RESUMO}

A gestão escolar é um dos pilares da educação que pode contribuir para construção social na formação plena do ser humano. O gestor escolar responsável interage, colabora, motiva e se relaciona mutuamente com seus companheiros para a obtenção dos objetivos pretendidos pela comunidade em benefício de uma educação de qualidade. Ao contextualizar esses hábitos e relacionamentos o presente trabalho objetiva compreender o quanto podem contribuir e interferir não só nas atividades deste profissional como também no dia a dia de todos os que integram o universo escolar. Assim sendo, o artigo aborda fundamentos constituído de livros, artigos, apostilas e trabalhos acadêmicos em torno dos hábitos de trabalho em grupo, do relacionamento interpessoal e das interações do gestor escolar. O estudo aponta que a ação pautada na interação como hábito de trabalho traz benefícios para a figura do Gestor Escolar dentro de suas atribuições como profissional. Além disso, melhora as

\footnotetext{
${ }^{1}$ Pós Graduação em Coordenação Pedagógica - Faculdade UniBF. E Gestão Escolar: Administração, Supervisão e Orientação - Instituto Superior de Educação Elvira Dayrell - Iseed. Licenciatura em Pedagogia - Instituto Superior de Educação São Judas Tadeu - 2014/ 2018.
} 
relações com os colegas, fazendo diferença na priorização da via democrática no espaço escolar e na sociedade.

Palavras-chave: Interação, relação interpessoal, hábitos, trabalho em grupo, gestão escolar.

\section{INTRODUÇÃO}

A educação no Brasil vem passando por constantes mudanças e transformações, exigindo cada vez mais dos profissionais da educação: comprometimento, gestão, responsabilidade social e empenho. Por isso, apresenta-se neste artigo a compreensão da importância das interações, dos relacionamentos interpessoais e hábitos de trabalho em grupo do Gestor Escolar em seu ambiente de trabalho, considerando aspectos de convívio, buscando seu papel nesse âmbito e suas atribuições que, muitas vezes, são de ordem organizacional, burocrática e demanda compreender a realidade escolar e o seu cotidiano. Analisando o trabalho do Gestor Escolar surgiram os seguintes questionamentos:

- Como o trabalho em grupo contribui para o desenvolvimento da escola?

- Como esse profissional pode gerir as próprias relações com outros colegas?

- Quais são suas funções e potencialidades dentro de seu campo de trabalho envolvendo o trabalho em grupo e as relações interpessoais?

Esses questionamentos mobilizam a analise no presente artigo e as funções dos Gestores que atuam nas escolas.

É necessário estar em constante diálogo com os diversos membros que fazem parte do processo de formação educacional: professores, coordenadores, supervisores, orientadores etc. Segundo Oliveira (2013) as atividades desempenhadas dentro da escolar devem ter comprometimento coletivo para que todos a experimentem, em outras palavras, o autor aponta para a reunião de posicionamentos que objetivam melhorar as práticas e competências, portanto, desencadeadoras de experiências legítimas e avançadas. 
De acordo com Orsolon (2006) a figura do Gestor Escolar compõe apenas um dos personagens atuantes na educação, o que torna fundamental pensar no trabalho vivenciado, compartilhado e não direcionado para a concretização de ações com formato singular de gestão.

Então, para levar-nos a um entendimento acerca dessa temática, procurou-se realizar uma pesquisa bibliográfica sobre o tema. Livros, teses, dissertações e artigos relacionados ao tema foram consultados, buscando suporte em diversos autores que tratam sobre o referido assunto, para assim, descrever e esclarecer as atribuições desse personagem protagonista de respeito no cenário educacional brasileiro. Tomamos como referências autores como Luck (2009), Araújo (2009), Vasconcelos (2009), Sousa (2017), Arantes (2013) Libâneo (2004) e outros para dar sustento às fundamentações. A seguir apresenta-se a Gestão Escolar, definições, contribuições, bem como o pensamento de vários teóricos, mais adiante o foco é no Diretor escolar, suas relações e seu papel democrático.

\section{GESTÃO ESCOLAR}

Segundo Silva e Sousa (2006, p. 24) Gestão escolar é o "ato de gerir a dinâmica cultural da escola e objetiva promover a organização, a mobilização e a articulação de todas as condições materiais e humanas necessárias para garantir o avanço dos processos sócio-educacionais". Isto posto, cabe à gestão escolar fortalecer e sustentar a cultura das escolas, com ações conjuntas e articuladas, visando resolver os problemas educacionais brasileiros. Ademais, é aceitável dizer que a gestão escolar retrata aspectos de grande importância para educação, uma vez que, por esse processo, se observa pela visão estratégica, os problemas que de fato ocorrem e prejudicam as intuições. De acordo com Sousa; Ferreira e Correia (2015, p. 5): "a gestão escolar constitui uma das áreas de atuação profissional da educação destinada a realizar o planejamento, a organização, a liderança, a orientação, a mediação, a coordenação, o monitoramento e avaliação dos processos necessários à efetivação das ações educacionais". 
Isto dito, em caráter abrangente, a gestão escolar engloba, de forma associada, o trabalho da direção escolar, da supervisão ou coordenação pedagógica, da orientação educacional e da secretaria da escola, considerados participantes da equipe gestora, além da participação da comunidade, dos pais e de organizações diversas para efetivá-la com qualidade necessária que a sociedade tecnológica da informação e do conhecimento demanda.

Nesse sentido, temos uma gestão participativa atrelada a um grupo de pessoas que objetivam tomar decisões agindo em equipe e tendo em raciocínio que o sucesso de uma organização precisa da ação de seus componentes, como postula Luck,1996:

O entendimento do conceito de gestão já pressupõe, em si, a ideia de participação, isto é, do trabalho associado de pessoas analisando situações, decidindo sobre o seu encaminhamento e agindo sobre elas em conjunto. Isso porque o êxito de uma organização depende da ação construtiva conjunta de seus componentes, pelo trabalho associada, mediante reciprocidade que cria um "todo" orientado por uma vontade coletiva. (LUCK, 1996, p.37).

Isso nos leva a reflexão da gestão democrática, onde se ver e rever a superação das relações autoritárias e se objetiva bons relacionamentos e bons hábitos de trabalho em grupo. Em vista disso, a gestão escolar, tal qual, Luck (2009) prega, tem o intuito racional direcionado para ações educativas de rendimento. Antes apoiadas aos propósitos das políticas educacionais, das finalidades educativas sociais e princípios que envolvem a formação de qualidade do ser humano.

Ao contrário do que afirma o autor acima, segundo Albuquerque (2015) ainda residem elementos da gestão centralizadora, onde as responsabilidades não são delegadas, nem distribuídas, tudo se desenrola nas mãos do Gestor Escolar, e este, muitas das vezes, governa e age com desconfiança.

Conforme Braga (2009 apud SANTOS, 2017, p. 36) essa "gestão centralizada tem origem numa cultura de poder e paternalismo, de desconfiança mútua, e baseadas em relações de dependências". Pode-se perceber que isso desmistifica a concepção de interação, participação, obstrui as boas relações humanas e pode tornar ineficaz tantos fatores que complementam a pura administração. 
Nesse novo cenário, Para Carvalho et al. (2008) especialmente quando se trata da gestão de escolas públicas, podemos dizer que é evidente, dentro da atuação prática do gestor escolar, o cumprimento da democratização que compreendem o ambiente de ensino, além disso, da mesma forma, se efetiva as diretrizes legais. Nesses termos, conforme pensa o autor, a preponderância da participação como inegável e, pensando nisso dentro do aspecto das relações que o gestor desenvolve dentro e fora dos muros da instituição, podemos refletir sobre como o trabalho em grupo contribui para à equipe e o desenvolvimento da escola.

Separada da atual polarizada e burocrática cultura Gestora, a compreensão da gestão escolar perfaz o âmbito comunicativo, cooperativo e compartilhado do sistema de ensino brasileiro e, ainda possui, o potencial de criar espaços onde se privilegia boas relações de trabalho. (HONORATO, 2018). Portanto, o compartilhamento de decisões e informações, o envolvimento da comunidade, alunos, professores, funcionários, a preocupação com a qualidade da educação e a transparência financeira nos ajuda a enxergar o quanto as interações do profissional interferem as relações no cotidiano institucional.

Conforme Albuquerque (2015, p.11) "uma atuação de forma democrática, participativa e descentralizada pode sim tornar o ambiente escolar melhor, visto que a partir dessa perspectiva se faz possível ter uma visão ampla e acolhedora desse espaço". Com isso, é preciso que a gestão democrática aconteça de fato e não se adote apenas a simples adoração de uma fala democrática para melhorar a estética dos modelos de gestão atuais.

De acordo com Dalmás (1994) a ação grupal é direcionada instintivamente a organização colaborativa para atingir os fins desejáveis, onde todos têm condições de se empenhar ativamente no trabalho. Entretanto, há situações que não é necessário ou não se exige o envolvimento de todos. Honorato (2018) considera que nem toda situação é intencionada para liderança participativa, em algumas circunstâncias a sensatez, a segurança na tomada de decisão empreendida é o suficiente. De certo é inegável, não é correto ressaltar que cada centímetro do ambiente escolar tem que haver liderança participativa. Dessa maneira, analisando o pensamento do autor é 
possível compreender que também têm aquelas situações observadas no cotidiano nas quais envolvem decisões a serem tomadas com implicação técnica, própria da vida dos que compõe a equipe gestora, sejam orientações administrativas ou pedagógicas.

\subsection{O GESTOR ESCOLAR - DIRETOR}

"A gestão do diretor se assenta, portanto, sobre liderar e compartilhar a liderança tanto na comunidade interna como externa da escola, orientando uma visão do conjunto do trabalho educacional e do funcionamento da escola [...]" (LUCK, 2009, p. 80). Com tal característica, é aconselhável não deixar de fora cada membro com potencial participativo, criativos e construtivo de ideias.

Araújo (2009) elenca que a gestão escolar carrega em suas costas critérios com funções responsáveis e impactantes no ambiente escolar, como exemplo, podemos citar a responsabilidade, envolvimento, desempenho e principalmente qualidade do processo ensino-aprendizagem. Isso significa que a atuação do diretor se dará através de uma participação compartilhada, com capacidade de liderança, sendo um gestor que assume responsabilidades. Igualmente, Luck, 2016 sustenta que:

Aos gestores das escolas compete, portanto, promover a criação e a sustentação de um ambiente propício a participação plena dos profissionais, alunos e pais, no processo social escolar, uma vez que é por essa participação que seus membros desenvolvem consciência e sentido de cidadania. (LUCK, 2006, p.18).

Dessa maneira o diretor, tendo em vista as convivências que se fixam em seu grupo de trabalho, pode-se tentar produzir e nutrir um ambiente oportuno, motivando o grupo, auxiliando no desenvolvimento de uma espírito de compromisso, para que a escola possa ter um elo maior de ligação com os docentes, que por sua vez, estes com os alunos e comunidade.

Santos (2017) enfatiza o papel do Gestor dentro da instituição, que exerce e colabora para construção e o gerenciamento das atividades. Além disso, ajuda como líder os colegas visando atingir resultados comprometidos com desenvolvimento educacional. 
Segundo o mesmo autor, o gestor deve ser um líder que acredita no potencial da equipe incentivando o espírito de cooperatividade. "Ele não é um chefe que apenas manda para ser obedecido e sim aquele que propõe desafios encorajando a inovação e a participação de todos" (SANTOS, 2017 p.40). Resultante desse pensamento, os gestores precisam criar espaços de decisão conjunta, identificar situações de dificuldade, avanços, prioridades, definindo estratégias e ações com responsabilidade dos resultados positivos para escola com objetivo principal do sucesso. Honorato (2018) reforça com o seguinte:

Os diretores de escolas eficazes relacionam o estilo de liderança adequado de acordo com a situação, mas nunca poderão fugir do diálogo: o saber ouvir é mais importante, às vezes, do que o ordenar. A gestão democrática e participativa que se deseja na unidade escolar é muito mais do que um dever fazer simplesmente, ela é uma construção social e histórica que cria raízes fortes na formação plena do aluno, como ser humano, cidadão, autônomo e ético, pronto para viver em sociedade (HONORATO, 2018, p 35) .

Posto isso, é de substancial importância para o gestor respeitar as diferenças, os ponto de vista, fomentar o diálogo para que isso se transforme em bons hábitos de trabalho cooperativo. Libâneo (2004) expõe que muitos dirigentes escolares foram criticados por práticas fielmente burocráticas e centralizadoras o que torna importante saber quais papéis, na sociedade atual, compete aos diretores.

Nessa perspectiva de liderança participativa estão as práticas do gestor escolar que são: "zelar pela realização dos objetivos educacionais, pelo bom desempenho de todos os participantes da comunidade escolar para que se atinja padrões de qualidade definidos pelo sistema de ensino" (LUCK, 2009, p. 22).

\subsection{RELAÇÕES INTERPESSOAIS DO GESTOR ESCOLAR}

Ao observar com quantas pessoas diferentes nos relacionamos, diferentes pensamentos, culturas, religiões, gênero, maneira de se vestir, idade, habilidade para lidar com as novas tecnologias entre outras, enxergamos como esta reunião de diferentes percepções pode valorizar a formação do nosso conhecimento. Na medida em que nós compreendemos que este é um processo que possibilita contribuir para 
nosso próprio crescimento pessoal e profissional, fica ainda mais interessante conviver com pessoas cujas características são tão diferentes. De acordo com Santos (2017) o Gestor Escolar deve ser um elemento impulsionador e promotor de boas relações, engaja-se de forma interativa entre todos os seus colaboradores. Grande parte do trabalho é feita por meio de contato com os outros, quer como indivíduos, quer como grupo. A partir disso e como exemplo, a autora complementa o raciocínio dizendo que

O relacionamento interpessoal na área escolar exige entre outras coisas, habilidades de trabalhar em equipe, pois todos os membros de um grupo são coletivamente responsáveis por seu funcionamento; saber que neste contexto irão sempre surgir momentos de tensão, conflitos, etc. é preciso considerar que esses fatores podem facilitar ou bloquear relacionamentos primordiais, criar um clima de respeito, confiança e buscar estar sempre atento e possibilitar uma boa qualidade nos processos de fundamento e relacionamento na instituição (SANTOS, 2017, p.11).

É possível notar que essa reflexão impõe aos gestores que estabeleçam rotinas de trabalho e formas de relacionamento favoráveis com os funcionários, possibilitando um ambiente muito mais agradável. No entanto, Vasconcellos (2002) chama a atenção para alguns diretores que mandam e desmandam, tratam os equipamentos da escola como se fossem objetos pessoais, propriedades privadas; outros, ao contrário, ramificam relações de parceria com a comunidade e, com isto, não só passam a contar com ela como elemento de apoio para as mudanças, como ainda obtém diminuição do vandalismo, da violência; os alunos se sentem acolhidos, experimentam a escola como um lugar afim. Luck (2009) amplia as discussões em torno, argumentando que

Educação é processo humano de relacionamento interpessoal e, sobretudo, determinado pela atuação de pessoas. Isso porque são as pessoas que fazem diferença em educação, como em qualquer outro empreendimento humano, pelas ações que promovem, pelas atitudes que assumem, pelo uso que fazem dos recursos disponíveis, pelo esforço que dedicam na produção e alcance de novos recursos e pelas estratégias que aplicam na resolução de problemas, no enfrentamento de desafios e promoção do desenvolvimento (LUCK, 2009, p. 82). 
É primordial desenvolver ações internas nas instituições, que sejam conduzidas por boas relações no sentido de cultivar um clima positivo que faça com que as pessoas se sintam motivadas, comprometidas com os objetivos. Em meio a isso, a comunicação dá a oportunidade de oferecer, para as lideranças e integrantes da equipe, conversar claramente sobre as questões envolvidas no cotidiano das instituições. "Principalmente em reuniões ou encontros, onde se pode valorizar as trocas simultâneas de informações, o feedback e o esclarecimento de dúvidas importantes" (ARANTES, 2013, p. 65).

Kroth (2008) enfatiza que é fundamental que se estabeleça um clima de constante diálogo e entendimento uma vez que a escola, em sua totalidade, visa também construir um ambiente de alegria, satisfação e confiança, estabelecendo um clima descontraído.

Mailhiot (1976, p. 66), em uma de suas pesquisas realizadas, o psicólogo afirma que chegou à constatação de que "a produtividade de um grupo e sua eficiência estão estreitamente relacionadas não somente com a competência de seus membros, mas sobretudo com a solidariedade de suas relações interpessoais".

Segundo Arantes (2013) Numa instituição, as equipes de trabalho são formadas por pessoas cujas diferenças precisam ser valorizadas no sentido de promover a integração de todos e um ambiente de trabalho favorável. Podemos citar, dessa forma, a abertura da escola à comunidade. Nisso se inclui a comunidade a qual pertence como estratégia que pode colaborar para o bom andamento do trabalho educativo. Com isso, o desenvolvimento de ações que favorecem a união dos membros na equipe de trabalho é elevado a tal importância que se pense no processo de reflexão educativa.

\section{CONSIDERAÇÕES FINAIS}

A Gestão Escolar exige diferentes conhecimentos, competências e habilidades gerais e específicas. Gestor Escolar é um dos agentes de ensino, sua atuação no processo educacional é notável. Ele tem como função impulsionar todos os personagens e 
elementos que fazem parte do sistema de ensino para concretização do ensino/aprendizagem com qualidade para todos.

Compreendemos que é inerente ao trabalho desse profissional ter boa vivência no trabalho em grupo, ter uma boa conduta, relações interpessoais saudáveis e um papel o interativo por meio da gestão participativa. Então, dessa forma, ele precisa estar atento à complexidade e a diversidade das situações pedagógicas existentes em sua escola, compreender que desempenha um papel fundamental na formação da personalidade humana.

Gerir, então, o complexo de relações humanas deixa de ser algo apenas ligado em aspectos administrativos e burocráticos. Com isso a função do gestor escolar se configura como uma das mais fundamentais atividades no âmbito da educação e na criação e desenvolvimento dessa sociedade, dessa maneira há necessidade da competência de liderança na sua ação pedagógica-administrativa.

Contudo, este trabalho não se finaliza aqui, apenas, por outro ângulo, estimula as próximas pesquisas que poderão ampliar os estudos sobre este tema, assunto este que almeja um maior detalhamento. Assim, mormente, com estas considerações finais, propõe-se um incentivo a reflexão com relação a importância deste profissional na educação, desencadeador de uma nova postura educativa.

\section{REFERÊNCIAS}

ALBUQUERQUE, Cindia Maria Braga. GESTÃO DEMOCRÁTICA NA ESCOLA: A BUSCA POR UM OLHAR PEDAGÓGICO E DESCENTRALIZADO TERÁ SIDO ALCANÇADO? IN Congresso de inovação pedagógica em Arapiraca. VII., 2015, Campus Arapiraca. Anais do Congresso de Inovação Pedagógica em Arapiraca. Universidade Federal de Alagoas (IFAL). Disponível em :< https://www.seer.ufal.br /index.php/cipar/index>. Acesso em 19 de agost de 2020.

ARANTES, Elaine. Ética e relações interpessoais. Rede e-etc Brasil. Instituto Federal do Paraná. Curitiba-PR. 2013. 
ARAUJO, Dourisete. LIDERANÇA E MOTIVAÇÃO NA GESTÃO ESCOLAR. [online] Gestão Escolar. 12/09. Disponível em < http://gestaoescola.blogspot .com/2009/12/lideranca-e-motivacao-na-gestao-escolar.html > Acesso em 09 de ago. 2019.

BRAGA, J.; BRITO, L. (2009). Perfil ideal de competência profissional de gestores da área de saúde. In: Encontro de Gestão de Pessoas e Relações de Trabalho, 2, Curitiba.

CARVALHO, Elma Júlia Gonçalves de. et al. Gestão escolar. 22ª ed. Maringá, PR: Secretaria de Estado da Educação do Paraná - SEED: Universidade Estadual de Maringá, Programa de Desenvolvimento Educacional - PDE, 2008.

DALMÁS, A. Planejamento participativo na escola. Elaboração, acompanhamento e avaliação. Petrópolis: Vozes, 1994.

HONORATO, Hercules Guimarães. A GESTÃO ESCOLAR E A LIDERANÇA DO DIRETOR: DESAFIOS E OPORTUNIDADES. Revista Administração Educacional. Recife-PE, V. 9 N. 2 p. 21-37, jul/dez, 2018. Disponível em: $<$ https://periodicos.ufpe. br/revistas/ADED/article/view/239949>. Acesso em 20 de agost de 2020.

KANAANE, R. Comportamento humano nas organizações: o homem rumo ao século XXI. São Paulo: Atlas, 1995. MAILHIOT, G. B. Dinâmica e gênese dos grupos. 3. ed. São Paulo: Livraria Duas Cidades, 1976.

KROTH, Lídia Maria. Competências e atribuições do Orientador Educacional. Disponível em: www.psicopedagogia.com.br/artigos/artigo.asp?entrD=1072. Acesso em 29 jun. 2012.

LIBANEO, J. C. Organização e gestão da escola: teoria e prática. 5 ed. Revista e ampliada. Goiânia: Alternativa, 2004. 
LUCK, Heloisa. Dimensões da gestão escolar e suas competências. $1^{\circ}$. Ed. Curitiba: positivo, 2009.

LÜCK, Heloísa. A escola participativa: o trabalho do gestor escolar. 2. ed. Petrópolis: Vozes, 2006.

OLIVEIRA, Juscilene da silva; GUIMARÃES, Maria Campos Moraes. O papel do coordenador pedagógico no cotidiano escolar. R.C.C.E.S.A.R. v. 1, n. 1, p. 95103 , 2013.

Disponível

em:

$<$ http://www.faculdadefar.edu.br/arquivos/revista- publicacao/files-19-0.pdf >.Acesso em: 24 out. 2017.

SANTOS, Carla Cristina Sousa dos. A INTERFERÊNCIA DAS RELAÇÕES INTERPESSOAIS NA GESTÃO ESCOLAR, 2017. F 162. Curso de Mestrado em Docência e Gestão da Educação. Faculdade de Ciências Humanas e Sociais Universidade Fernando Pessoa. Disponível em :<https://www.google.com/url?sa=t\&source=web\&rct=j\&url=https://bdigital.ufp.pt/bitstr eam/10284/6037/1/DM_Carla\%2520Santos.pdf\&ved=2ahUKEwjs6vb4_7zrAhWCHrk GHdGpAo0QFjABegQICxAG\&usg=AOvVaw2eDtunlJ-zOlJHVur_yvQb. Acesso em 16 de agost de 2020.

SILVA, Elisabeth F. da; BRITO, José Ribamar de; ANDRADE, Vera Lúcia Bahiense. Gestão Educacional. 2006. 40f. Faculdade Integrada do Brasil- FAIBRA. TeresinaPI, 2014.

SOUSA, Daiane Bueno de; CORREIA, Josiane Caroline de Sousa Salomão; FERREIRA, Thais Mirian. Gestão educacional no âmbito da educação de jovens e adultos [online]. UFMS. 10/15. Disponível em: <https://www. google .com/url?sa=t\&source=web\&rct=j\&url=http://educere.bruc.com.br/arquivo/pdf2015/22 141_11259.pdf\&ved=2ahUKEwjTgv3nwb3kAhVylbkGHV6TCGcQFjAJegQICBAB\&us g=AOvVaw38ah2hJLgobU3E_UFMD3QD>. Acesso em 06/09/ 2019.

VASCONCELLOS, C. S. Coordenação do trabalho pedagógico: do projeto político pedagógico ao cotidiano da sala de aula. São Paulo: Libertad, 2002. 
VIEIRA, Sofia Lerche. Educação e gestão: extraindo significados da base legal. In. CEARÁ. SEDUC. Novos Paradigmas de gestão escolar. Fortaleza: Edições SEDUC, 2005, p. 7-20.

Enviado: Setembro, 2020.

Aprovado: Setembro, 2020. 